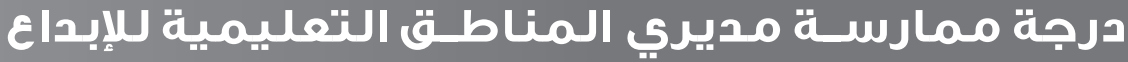

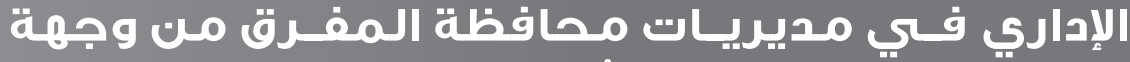

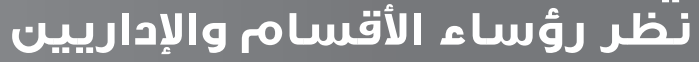

الاسـتلام : 28/نوفمبر/2020

التحكيــــ : 6 / ديسمبر / 2020

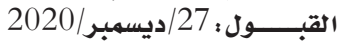

سلوى عايد السليحي)(1،)

(c) 2021 University of Science and Technology, Yemen. This article can be distributed under the terms of the Creative Commons Attribution License, which permits unrestricted use, distribution, and reproduction in any medium, provided the original author and source are credited.

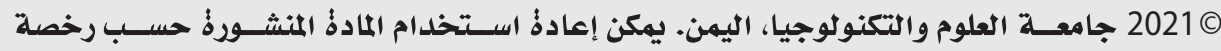
مؤسسة المشاع الإبلاعي شريطة الاستشهاد بالمؤلف والمجلة. 
درجة ممارسة مديري المناطق التعليمية للإبداع الإداري في مديريات

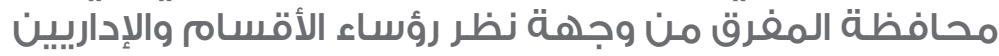

الملخص:

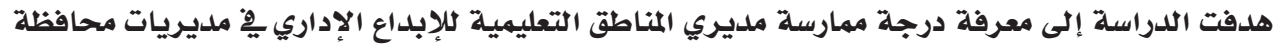

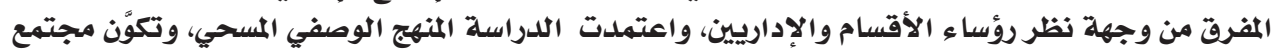

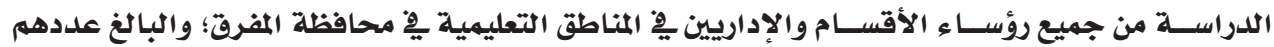

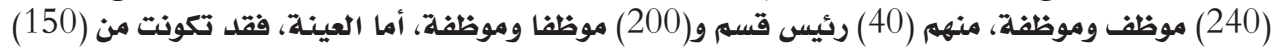

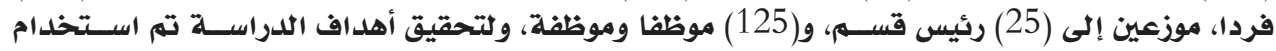

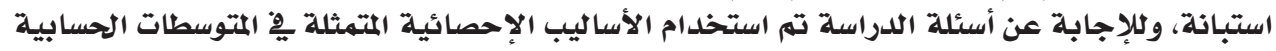

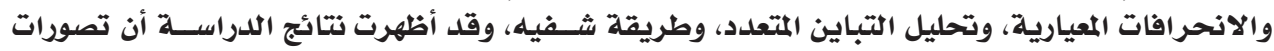

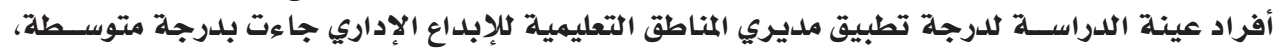

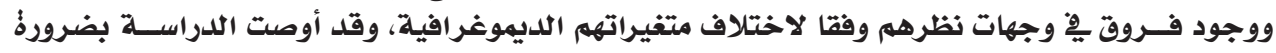

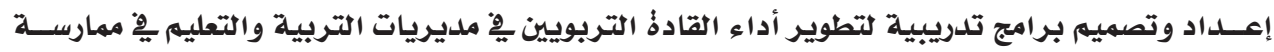
متطلبات الابتكار والإبلداع الإداري.

الكلمات المفتاحية : درجة ممارسة، الإبلاع الإداري، محافظة المفرق. 
سلوى عايد السليحي

المجلد الثاني عشر العدد (22) 2021م

\title{
Degree of Practicing Administrative Creativity by Education District Managers as Perceived by Department Heads and Administrators in the Districts of Mafraq Governorate
}

\begin{abstract}
:
The study aimed to assess the perceptions of department heads and administrators regarding the degree to which Educational District Managers practice administrative creativity in the districts of Mafraq governorate. To achieve this objective, the study followed the descriptive survey method, and used a questionnaire to collect data from the study sample which was selected from a population of 240 male and female employees (40 heads and 200 employees in education districts of Mafraq governorate). The sample consisted of (150) participants (25 department heads and 125 male and female employees). The data was analyzed by the use of statistical methods, such as means, standard deviations, the analysis of multiple variance and the method of Scheffe. The study findings revealed that the participants' degree of perception was moderate, and that there were differences in their perceptions according to their different demographic variables. The study recommended preparing and designing training programs to develop the performance of educational leaders in education districts to implement the requirements of administrative innovation and creativity.
\end{abstract}

Keywords: degree of practice, administrative creativity, Al-Mafraq Governorate. 


$$
\begin{aligned}
& \text { سلوى عايد السليحي } \\
& \text { المجلد الثاني عشر العدد (22) 2021م المايحم } \\
& \text { المقدمة: }
\end{aligned}
$$

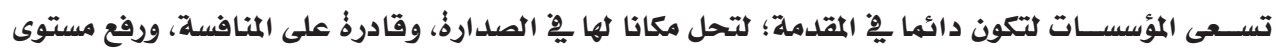

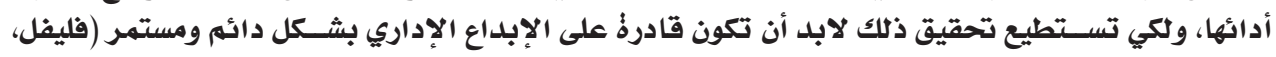
(2010

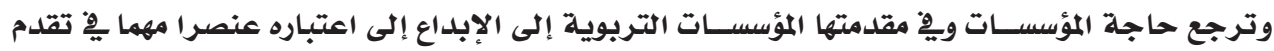

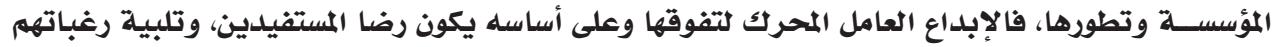

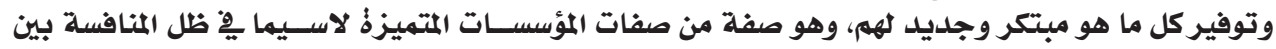

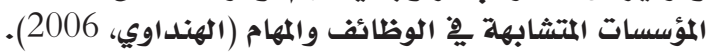

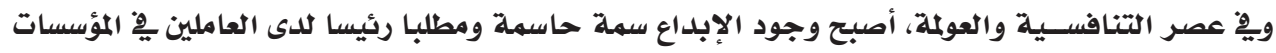

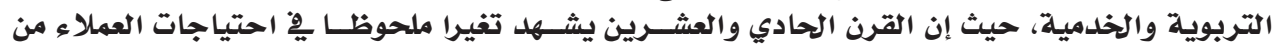

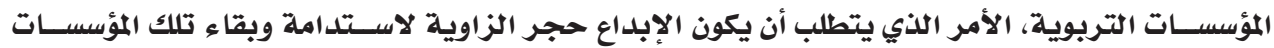

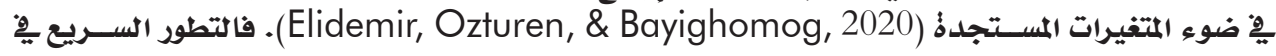
المنظمات التربويلة يتطلب من القائمين عليها والعاملين فيها مواكبة التطوات التطور الموجود، وبذل جهودهم ما أمكن

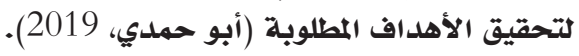

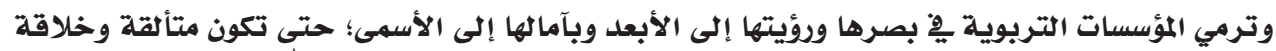

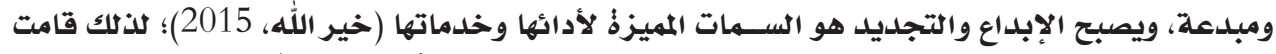

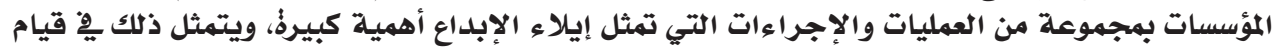

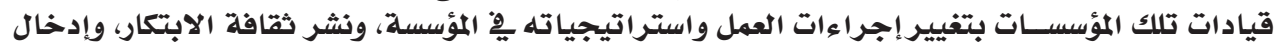

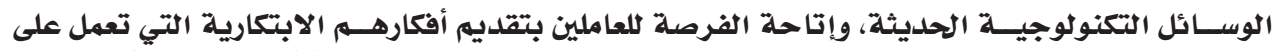

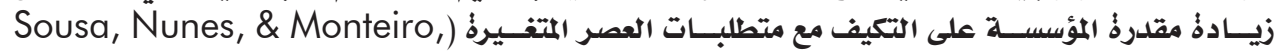

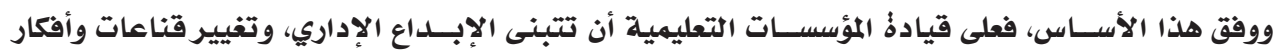

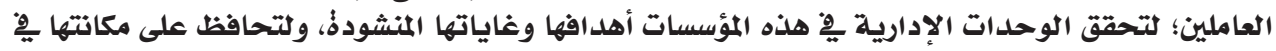

$$
\begin{aligned}
& \text { المجتهع، وتتميز عن مثيلاتها من المؤسسات الأخرى الودي. } \\
& \text { مشكلة الدراسة وأسئلتها: }
\end{aligned}
$$

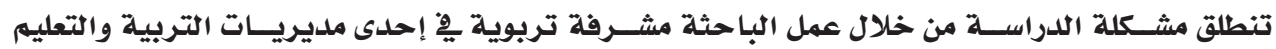

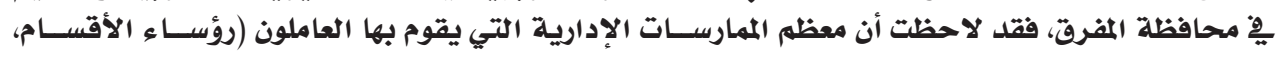

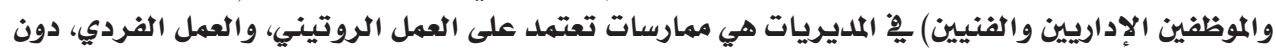

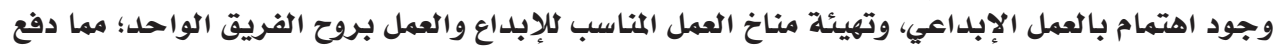

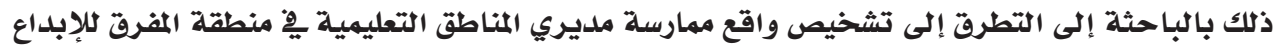
الإداري، ودرجة ممارستهم له إله.

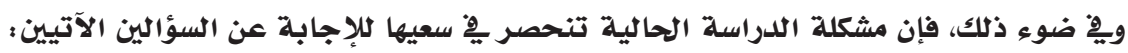

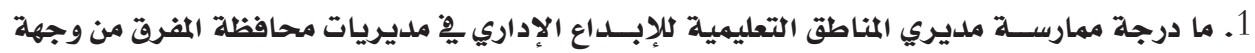

$$
\text { نظر رؤساء الأقسام والإداريين مائح }
$$

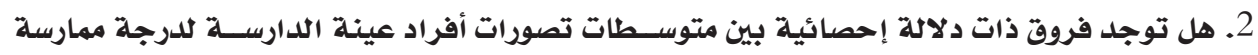

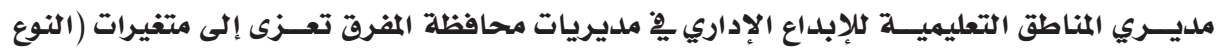

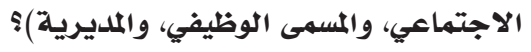


سلوى عايد السليحي

المجلد الثاني عشر العدد (22) 2021م السايل

وتتجلى أهداف الدراسلة فِِ الآتي:

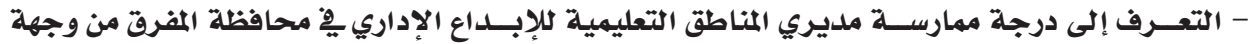
نظر رؤساء الأقسام والإداريين.

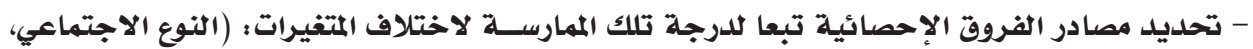
والمسمى الوظيفي، والمديرية). أهمية الدراسة:

تنطلق أهمية الدراسة من الآتي:

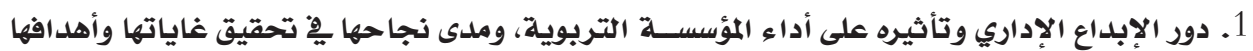

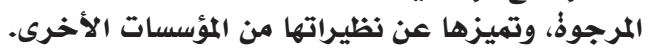

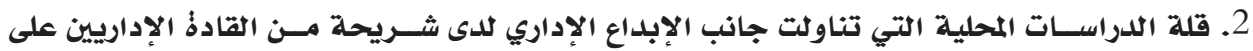

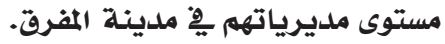

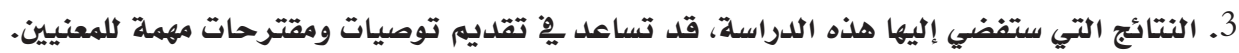

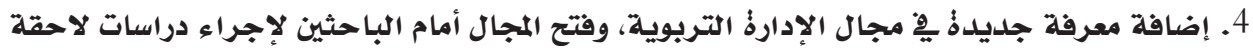

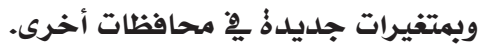

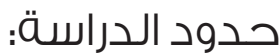

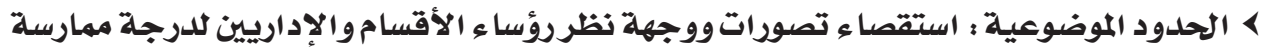

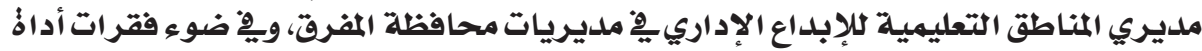

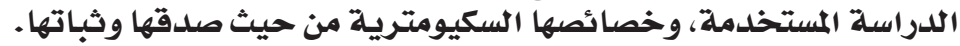
> الحلدود الزمنيـة : الفصل الثاني لعام (2020/2019).

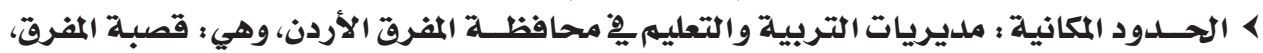

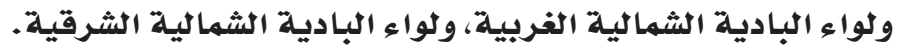

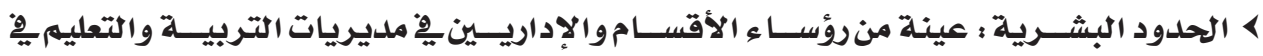
محافظة المفرق. مصطلحات الدراسة: محافة الإقدرق:

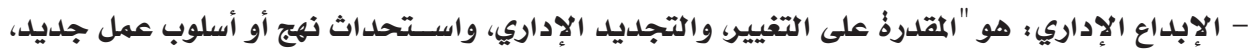

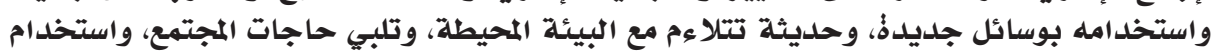

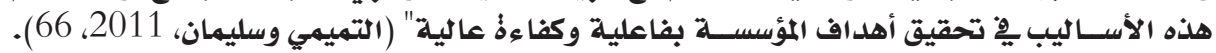

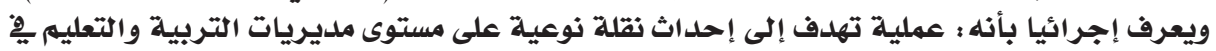

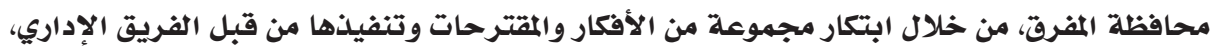

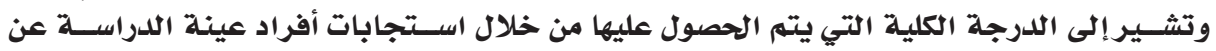

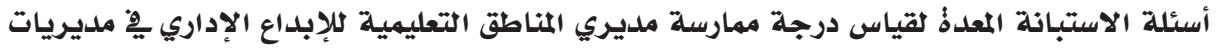
تربية وتعليم محافظة المفرق.

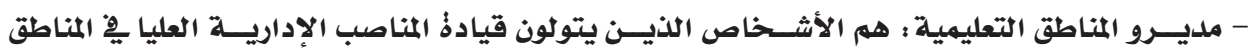

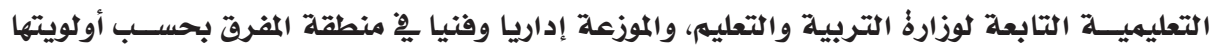
الجغرافية.

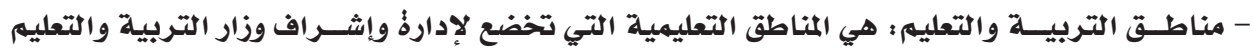

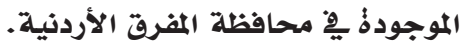


- رؤســاء الأقسـام والإداريين : هم الموظفون العاملون ِِّ مديريات التربيــة والتعليم التابعة لمحافظة المفرق وممن هم هِّ وظيفة رئيس قسه، وإداريين وفنيين. الأدب التربوي

يستعرض هذا الجزء الأدبيات التربوية المتعلقة بموضوع الإبلداع الإداري، وذلك على النحو الآتي:

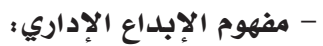

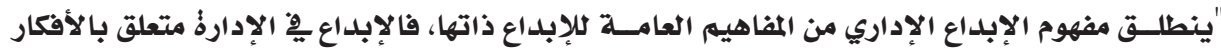

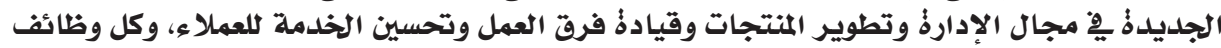

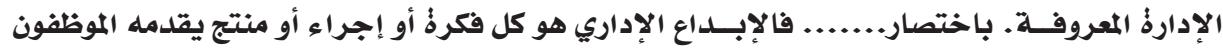

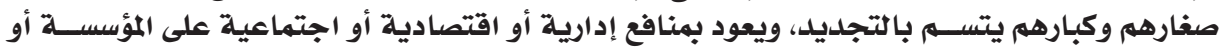

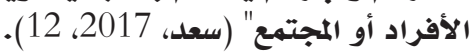

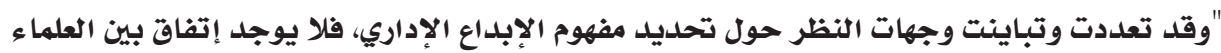

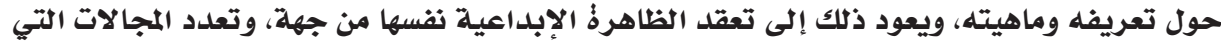

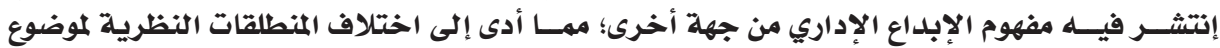

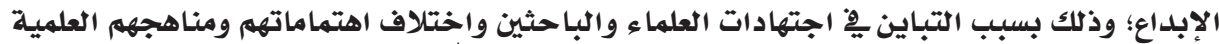

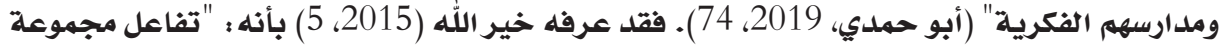

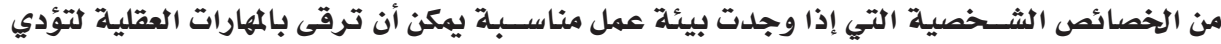

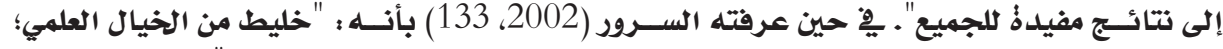

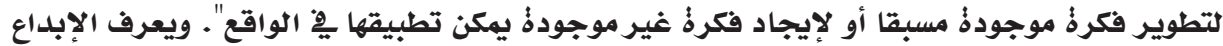

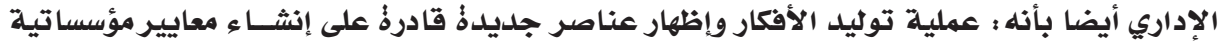

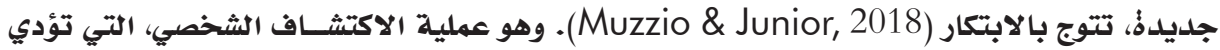

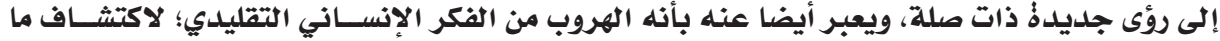
هو جديد وهادف (Aburuman, 2016).

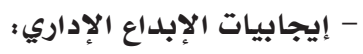

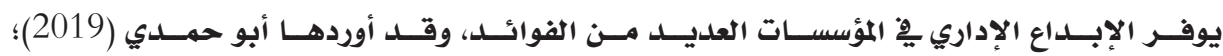

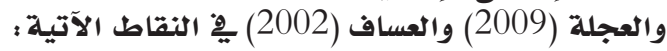

1. التكيف مع المتفيرات المحيطة، وبلدون تأثر سير العمليات الإدارية فِّ المؤسسة.

2. تطوير المنتجات المؤسسية بما يحقق الفائدةٌ للمؤسسة وموظفيها. 3. تغيير المعتقدات الذهنية للهوظفين.

4. التوظيف الفعال لموارد المؤسسة باستخلدام إجراءات تواكب الظروف الحالية.

5. إيجاد نوع من الانسجام بين السياسات التطويرية والموارد المؤسسية المتوفرةٌ.

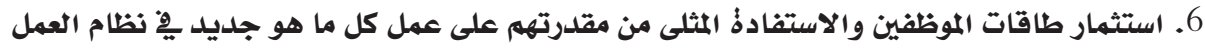

$$
\text { - عناصر الإبلداع الإداري: }
$$

1. الطلاقة : تقديم أكثر عدد من الألفاظ والأفكار والأثــكال التي تستوفِ شروطا معينة وِِّة وقت

قصير. 
سلوى عايد السليحي

المجلد الثاني عشر العدد (22) 2021م

2. المرونة : الانتقال من موقف إلى آخر، وهي ما تشير إلى مقدرةٌ المفكر المبلع على إنتاج استجابات

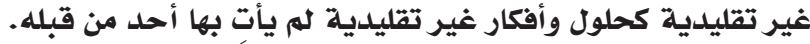
3. الأصاالة : إنتاج أفكار حليثة له تكن معروفة لأحد من قبل، وتتصف بالحداثة وعدم الانتشار. 4. المقدرةٌ : أي الإحساس بالمشكلات وإدراك طبيعتها، والتواصل إلى حلها. - مستويات الإبلداع الإداري :

صنف الصيريٍ (2003)، والسكارنة (2011) الإبداع الإداري إلى خمسة مستويات : 1. المستوى التعبيري : التلقائية التي يتصف بها شخص ما يِّ مجالات الأدب والفنون.

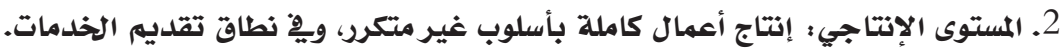

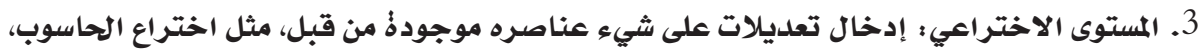

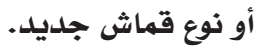

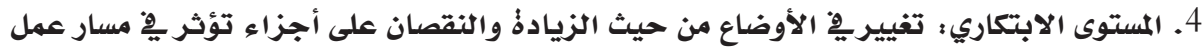

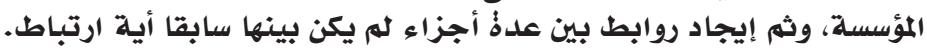

$$
\begin{aligned}
& \text { يشير إلى التطوير المستمر لكلأفكار، وينجم عن اكتساب مهارات جلديدأ. } \\
& \text { 5. المستوى التجلديدي : فتح آفاق جديدةُ لم يسبق الفرد إليها أحلد. } \\
& \text { - خصائص الشخص المبلدع: }
\end{aligned}
$$

يتمتع الشخص المبلع بمجموعة من الخصائص، أهمها (سعل، 2017) الآتي :

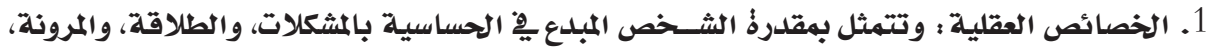

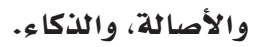

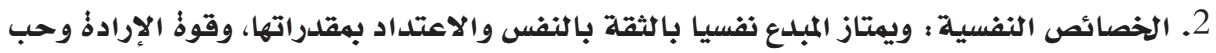

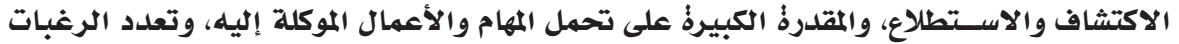

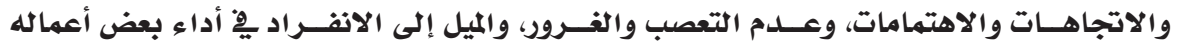

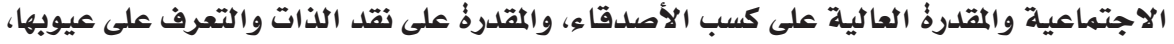

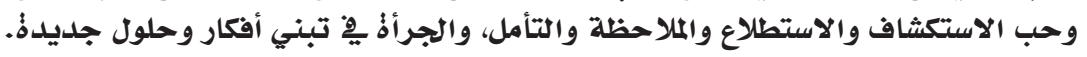

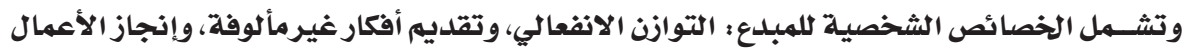

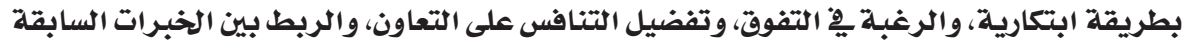

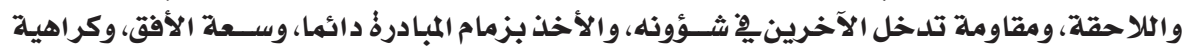

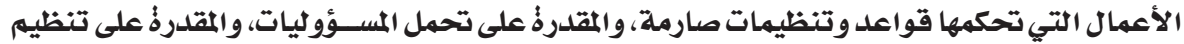

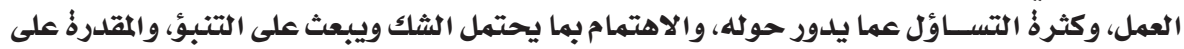

$$
\text { - معوقات الإبلاع دوافع الآخرين (جبرة، الإداري : 2010). }
$$

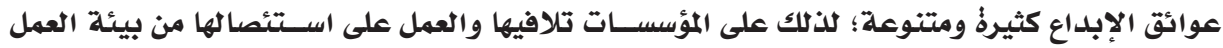

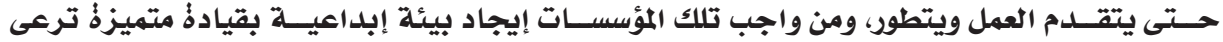

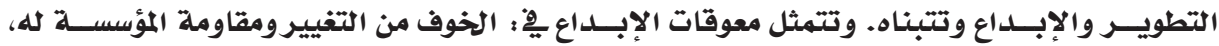

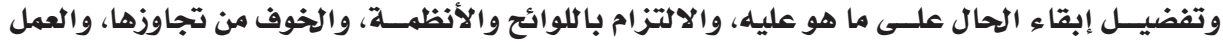

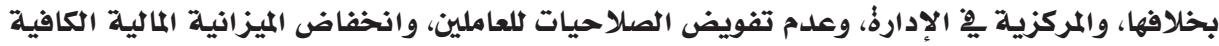

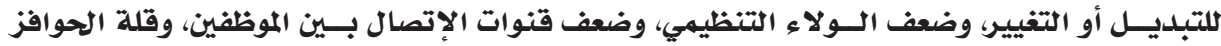
المادية والمعنوية (الهنداويلية التفيروض 2006). 
- أساليب تنهية الإبلاع الإداري:

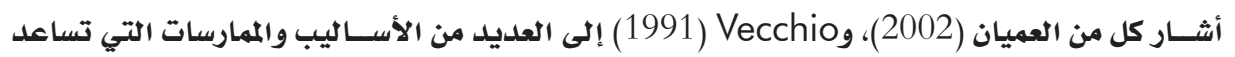

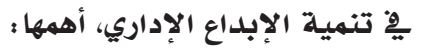
1. إثـارةٌ دافعية الموظفين لتقديم أفكارهم الإبداعية، مع الاســتماع إليها ودون التقليل من قيمتها وأهميتها. 2. توفير وسائل تواصل تسهح بتبادل ومناقشة المعلومات بين الموظفين. 3. حث الموظفين على المناظرةٌ بحرية؛ لتحفيزهم على تقديم معلوماتهم وآرائهم المبدعة. 4. تقديم الدعم المعنوي والمادي للمبلدعين، ورعاية مشاريعهم الجديدةٌ والمبتكرة. 5. منح الموظفين الاستقلالية يِّ التعبير عن أفكارهم وخطظهم الإبداعية. الدراسات السابقة:

للتعرف على واقع الإبلاع الإداري ستقوم الباحثة باستعراض بعض الدراسات العربية والأجنبية لها وفقا لتسلسلها الزمني من الأحدث إلى الأقدم.

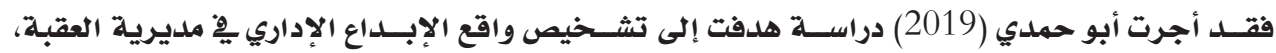

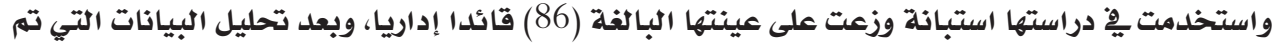

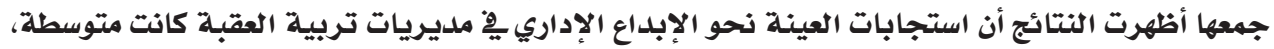

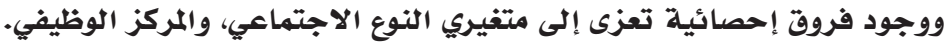

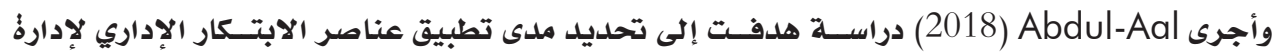

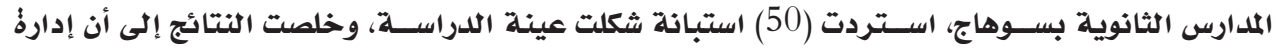

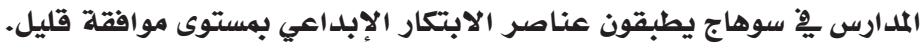

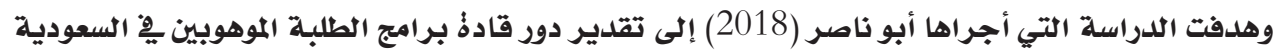

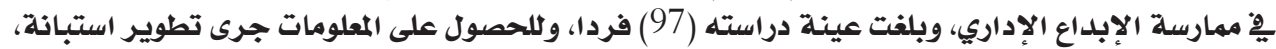

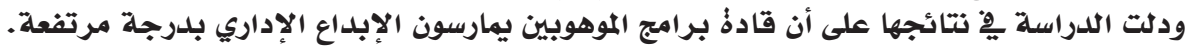

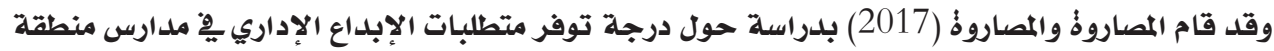

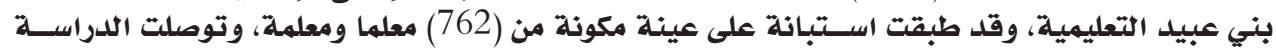

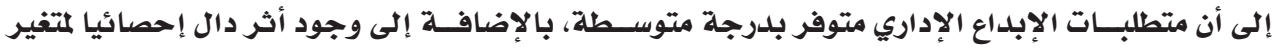
النوع الاجتماعي.

وقام Nwoko (2017) بلدراســة هدفت إلى تقويى درجة تطبيق مديري المرحلة الثانوية يِّة ولاية أبيا

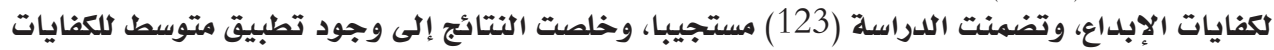
الإبلداعية عند مديري مداع وتفن الإبد المقاطعة.

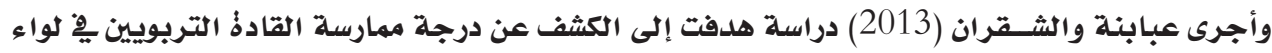

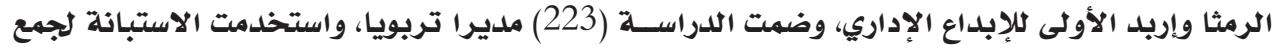

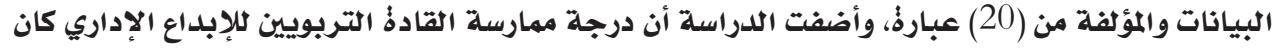

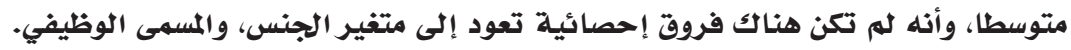

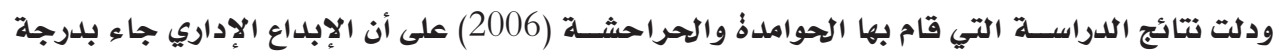

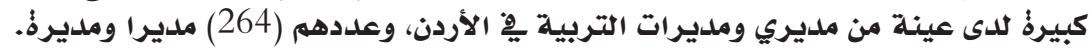
ومن خلال العرض السـابق للدراسات السابقة، يلاحظ تثـابه يِّ أهدافها، ويْ اعتمادها على الاستبانة 
سلوى عايد السليحي

المجلد الثاني عشر العدد (22) 2021م المايحي

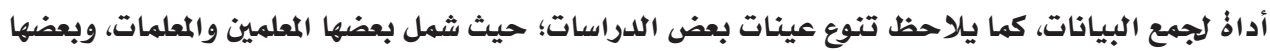

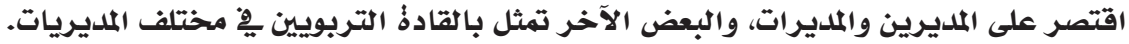

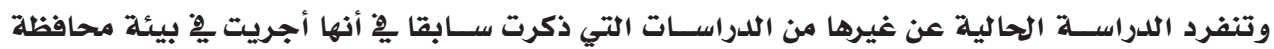

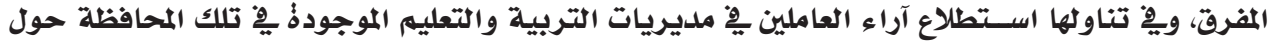

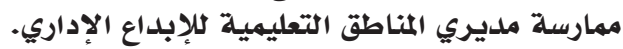

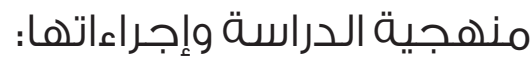
منهج الدراسلة :

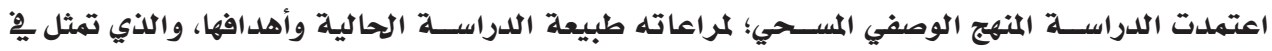

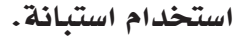

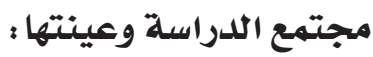

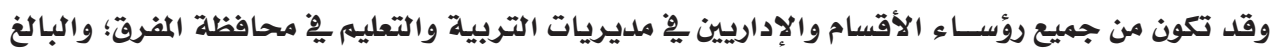

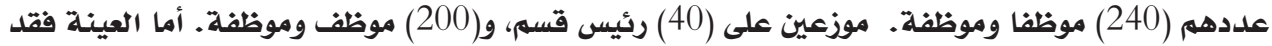

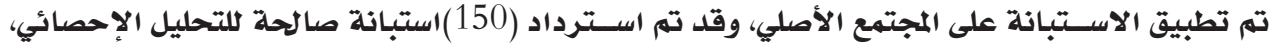

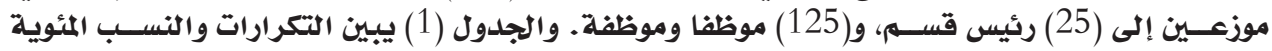
لأفراد الدراسة تبعا لفئاتهم.

جدول (1): توزيع الأفراد المستجبين لأداذ الدراسة وفق المتغيرات المستقلة

\begin{tabular}{|c|c|c|c|}
\hline النسبة المئوية & العدد & الفئة & المتغير \\
\hline 0.63 & 94 & ذكور & النوع الاجتماعي \\
\hline 0.37 & 56 & إناث & \\
\hline 0.17 & 25 & رؤساء أقسام & المسمى الوظيفي \\
\hline 0.83 & 125 & موظفون (إداريون وفنيون) & \\
\hline 0.23 & 35 & قصبة المفرق & المديرية \\
\hline 0.35 & 52 & البادية الغربية & \\
\hline 0.42 & 63 & البادية الشرقية & \\
\hline 100.0 & 150 & $\varepsilon$ & \\
\hline
\end{tabular}

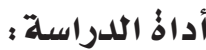

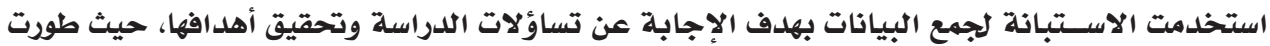

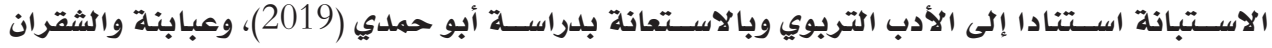

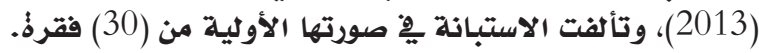

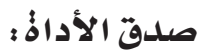

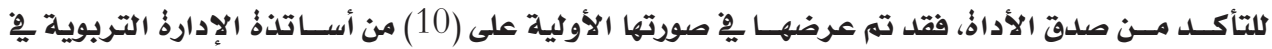

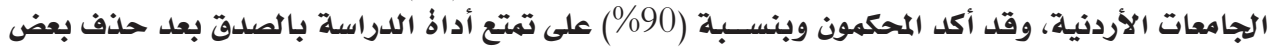

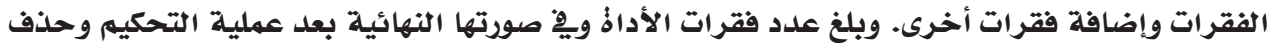
بعضها (23) فقرةً. 


$$
\begin{aligned}
& \text { سلوى عايد السليحي } \\
& \text { المجلد الثاني عشر العدد (22) 2021م }
\end{aligned}
$$

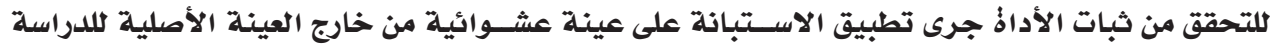

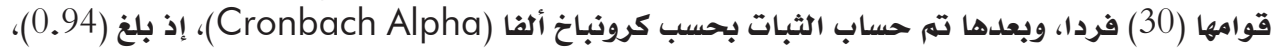

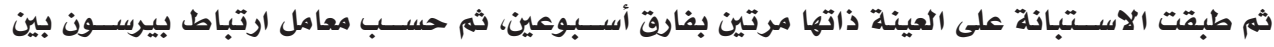

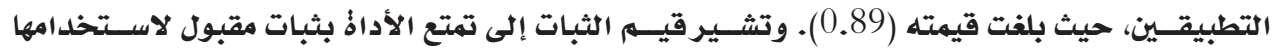

لغايات هذه الدراسة.

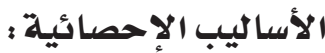

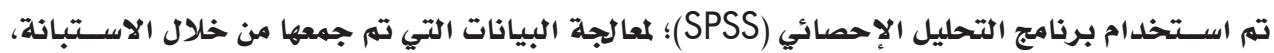

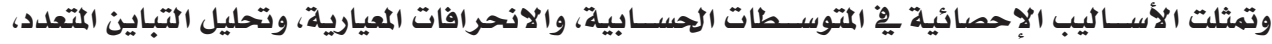

وطريقة شفيه.

عرض ومناقشة النتائج:

وفيما يأتي استعراض لنتائج الدراسة ومناقشتها ِِِ ضوء أسئلتها :

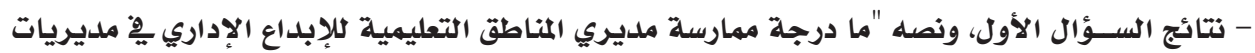

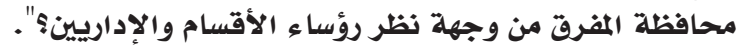

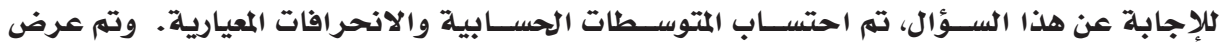

\begin{tabular}{|c|c|c|c|c|c|}
\hline دارمارسة & الانحريارية & الحتوسابطات & 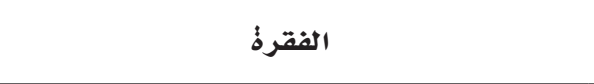 & 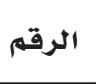 & الرتبة \\
\hline متوسطة & 0.73 & 3.40 & يوظف المديرون الوسائل التكنولوجية الحديثة يِّ أداء & 1 & 1 \\
\hline متوسطة & 0.68 & 3.39 & يحرص المديرون على جمع البيانات والمعلومات من & 3 & 2 \\
\hline متوسطة & 0.68 & 3.38 & يمتلك المديرون مهارات الحوار والمناقشة. & 6 & 3 \\
\hline متوسطة & 0.94 & 3.36 & يمتلك المديرون المقدرة على إدارة الأزمات. & 5 & 4 \\
\hline متوسطة & 1.38 & 3.34 & 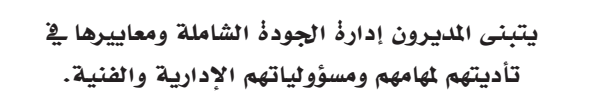 & 8 & 5 \\
\hline متوسطة & 0.97 & 3.31 & يمتلك المديرون المقدرةُ على التنبؤ بالمشكلات قبل & 4 & 6 \\
\hline متوسطة & 0.95 & 3.29 & يعمل المديرون على تبسيط الإجراءات الإدارية. & 9 & 7 \\
\hline متوسطة & 1.00 & 3.26 & 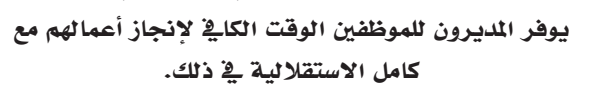 & 11 & 8 \\
\hline متوسطة & 1.20 & 3.24 & يفوض المديرون الصلاحيات والمسؤوليات للموظفين. & 10 & 9 \\
\hline متوسطة & 1.89 & 3.22 & يعمل المديرون على تلبية الاحتياجات التدريبية والمهنية. & 20 & 10 \\
\hline متوسطة & 0.65 & 3.22 & يتابع المديرون تدريب الموظفين وتأهيلهم. & 21 & 11 \\
\hline متوسطة & 0.95 & 3.20 & يشجع المديرون الموظفين على العمل بروح الفريق الواحد. & 12 & 12 \\
\hline متوسطة & 0.98 & 3.18 & يوفر المديرون مناخ وظيفي يشجع على الإبداع. & 13 & 13 \\
\hline متوسطة & 1.26 & 3.16 & يشجع المديرون الأفكار الإبداعية لدى الموظفين. & 15 & 14 \\
\hline
\end{tabular}

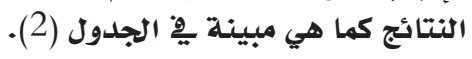

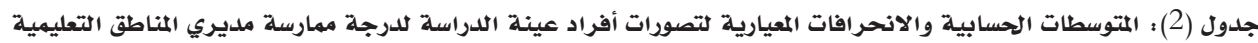

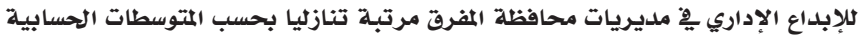


جدول (2) : يتبع

\begin{tabular}{|c|c|c|c|c|c|}
\hline درجمة & الانحصرافات & المحسابية & 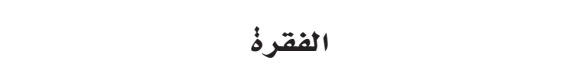 & الرقم & الرتبـة \\
\hline متوسطة & 1.25 & 3.14 & يسمح المديرون للموظفين بالتعبير عن آرائهم ولو كانت & 14 & 15 \\
\hline متوسطة & 1.25 & 3.12 & يشجع المديرون التنافس بين الموظفين لدفعهم للتوصل إلى & 16 & 16 \\
\hline متوسطة & 1.24 & 3.10 & يسترشد المديرون بآراء الموظفين وأفكارهم الإبداعية. & 17 & 17 \\
\hline متوسطة & 1.26 & 3.08 & يشجع المديرون تنفيذ الأفكار الإبداعية. & 18 & 18 \\
\hline متوسطة & 0.81 & 3.05 & يقدم المديرون أفكارا جديدةُ للعمل يِّ المديرية. & 2 & 19 \\
\hline متوسطة & 0.82 & 3.02 & والأصالة، والمرونة، والتفاصيل، والحساتل الإساسية للمشكلات). & 7 & 20 \\
\hline متوسطة & 0.85 & 2.95 & يختار المديرون الأفراد وفقا لقدراتهم الإبداعية. & 19 & 21 \\
\hline متوسطة & 0.81 & 2.90 & يقدم المديرون الحوافز المعنوية لأصحاب الأفكار & 23 & 22 \\
\hline متوسطة & 0.79 & 2.85 & يقدم المديرون الحوافز المادية لأصحاب الأفكار & 22 & 23 \\
\hline متوسطة & 0.29 & 3.18 & المتوسط الحسابي الكلي للأداذ & & \\
\hline
\end{tabular}

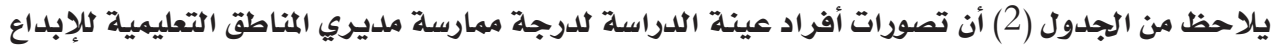

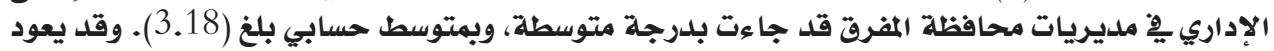

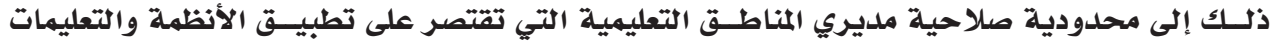

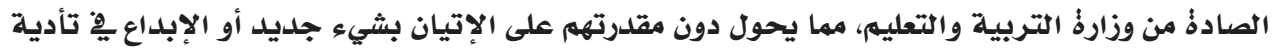

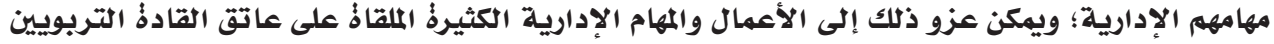

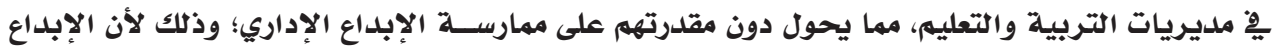

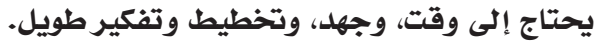

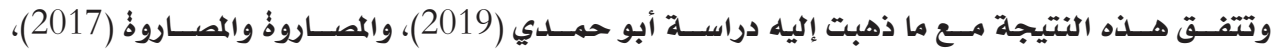

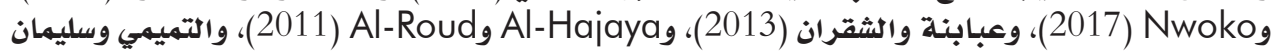

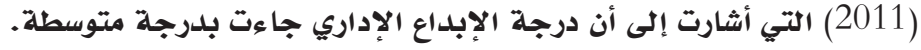

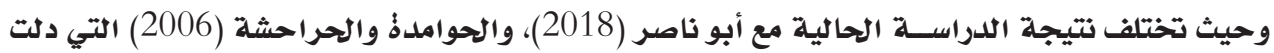
نتائجها على أن الإبلداع الإداري كان كبيرا.

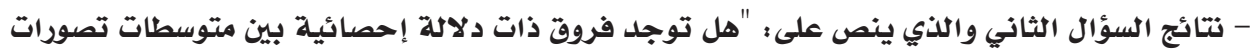

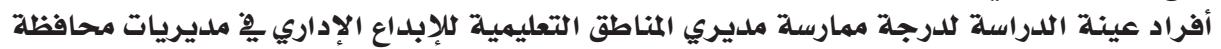

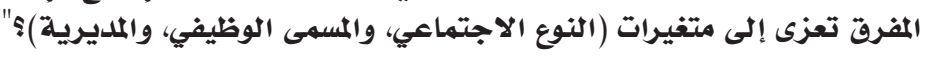
ولإجابة عن هذا الســؤال، تم اســتخراج المتوسطات الحسابية والانحرافات المعيارية . كما هو موضح

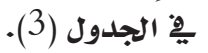


جدول (3) : المتوسطات الحسابية والانحرافات المعيارية لدلالة الفروق الإحصائية تبعا لكل من النوع الاجتماعي، والمسمى

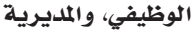

\begin{tabular}{|c|c|c|c|c|}
\hline الانحرافات المعيارية & المتوسطات الحسابية & العدد & الفئة & المتغير \\
\hline 0.26 & 3.30 & 94 & ذ ذكور & النوع الاجتماعي \\
\hline 0.28 & 3.06 & 56 & إناث & \\
\hline 0.29 & 3.18 & 150 & المجموع & \\
\hline 0.17 & 2.97 & 25 & رؤساء الأقسام & المسمى الوظيفي \\
\hline 0.28 & 3.39 & 125 & الموظفين (الإداريين والفنيين) & \\
\hline 029 & 3.18 & 150 & المجموع & \\
\hline 24 & 3.12 & 35 & قصبة المفرق & المديرية \\
\hline 28 & 3.32 & 52 & لواء البادية الشمالية & \\
\hline 29 & 3.11 & 63 & لواء البادية الشمالية & \\
\hline 0.29 & 3.18 & 150 & المجهوع & \\
\hline
\end{tabular}

يتضح من الجدول (3) وجود فروق ظاهريـة بين المتوسطات تعزى إلى (النوع الاجتماعي، والمسمى الوظيفي،

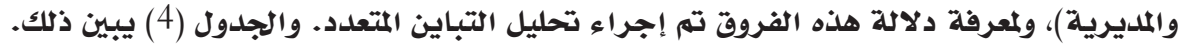
جدول (4): تحليل التباين المتعدد لدلالة الفروق الإحصائية تبعا لاختلاف المتغيرات المستقلة

\begin{tabular}{|c|c|c|c|c|c|}
\hline مستوى الدلاكة & $\mathrm{F}$ & متوسط لمربعات & درجات الحريـة & مجموع المربعات & مصدر التباين \\
\hline${ }^{*} 0.000$ & 16.143 & 0.932 & 1 & 0.932 & النوع الاجتماعي \\
\hline$* 0.000$ & 31.188 & 1.801 & 1 & 1.801 & المسمى الوظيفي \\
\hline \multirow[t]{3}{*}{${ }^{*} 0.006$} & 5.342 & 0.309 & 2 & 0.617 & المديرية \\
\hline & & 0.058 & 145 & 8.373 & الخطأ \\
\hline & & & 149 & 11.723 & المججموع الكلي \\
\hline
\end{tabular}

تظهر نتائج التحليل وجود فروق دالة إحصائيا لكل من: الهائ

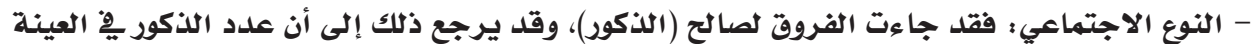

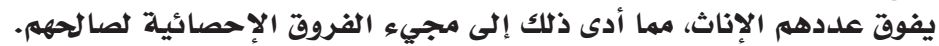

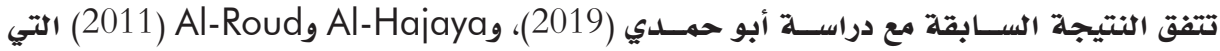

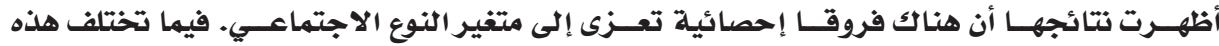

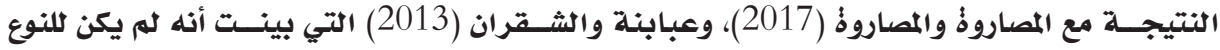
الاجتهاعي أبي دلالة إحصائية.

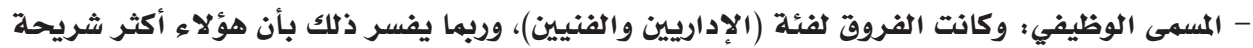

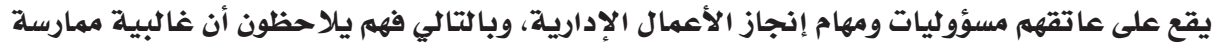

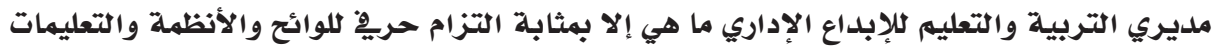

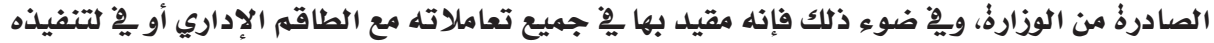

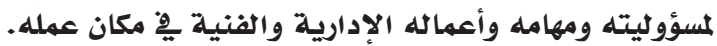

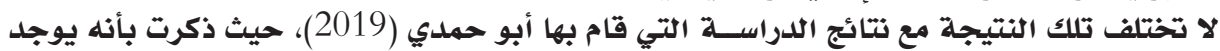

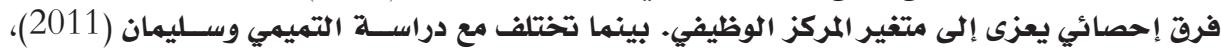

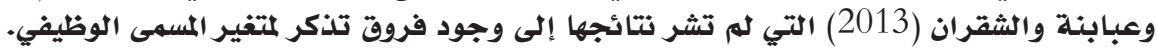


سلوى عايد السليحي

المجلد الثاني عشر العدد (22) 2021م السيدي

- المديريــة : ولتحلديل مصـــادر الفروق الإحصائية، اســتخدمت طريقة ثـفيه (Scheffe) للمقارنات البعلدية. والجدول ولتحليد (5) يوضح ذلك.

جدول (5): شفيه (Scheffe) للمقارنات البعدية لبيان مصادر الفروق الإحصائية بين المتوسطات

\begin{tabular}{|c|c|c|c|c|}
\hline الشمالية البراءية الشية & الشمالية الغربية الفية & قصبة & المتوسطات الحسابي & الملديرية \\
\hline 0.01 & ${ }^{*}-0.20$ & $\overline{--------}$ & 3.12 & قصبة المفرق \\
\hline${ }^{*} 0.21$ & ------------ & ${ }^{*} 0.20$ & 3.32 & لواء البادية الشمالية الغربية \\
\hline ----------- & ${ }^{*}-0.21$ & -0.01 & 3.11 & لواء البادية الشمالية الشرقية \\
\hline
\end{tabular}

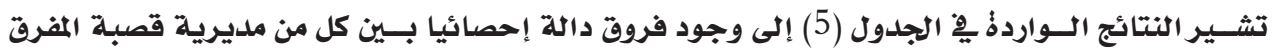

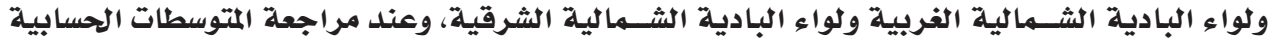

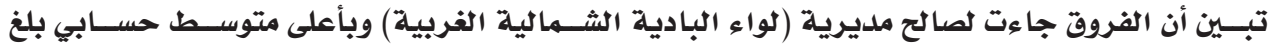

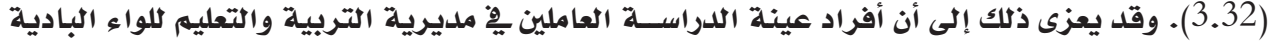

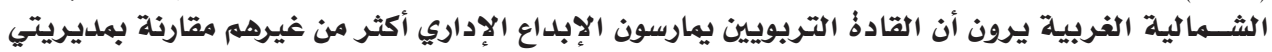

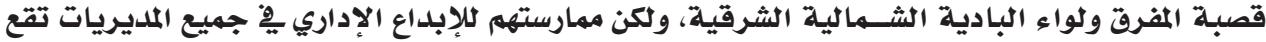
ضمن حلدود الدرجة المتوسطة ولكن وبلدرجات متفاوتة تبينها المتوسطات الحسابية لكل ملديرية الإلة الكارية

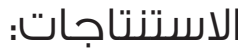
خلصت الدراسة إلى النتائج الآتية :

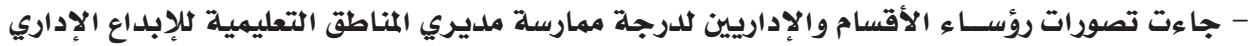
هِيْ مديريات محافظة المفرق بلدرجة متوسطة. - وجود فروق إحصائية تعود إلى النوع الاجتماعي لصالح (الذكور)، والمسمى الوظيفي لصالح (الإداريين والفنيين) والمديرية لصالح مديرية (البادية تصود إلى الإية الشمالية الفربية).

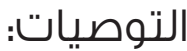
بناء على ما أسفرت عنه نتائج الدراسة الحالية، فإن الباحثة توصى بالآتي:

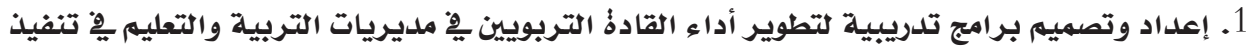
متطلبات الابتكار والإبداع الإداري.

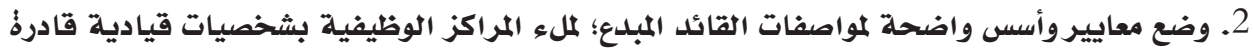
على الإتيان بأفكار غير مألوفة، مع إعلدادهم وتأهيلهم على نحو يضمن تطبيقهم للأداء الابتكاري يِّات

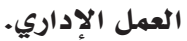

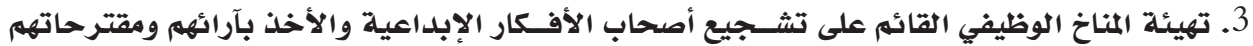

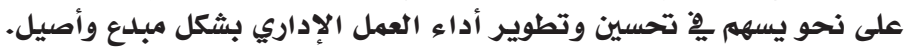

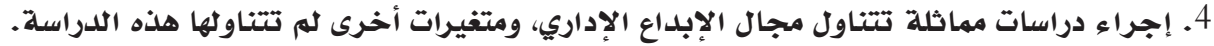

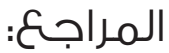

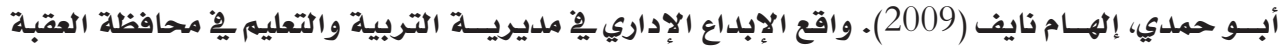

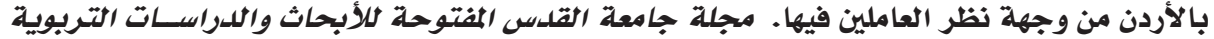

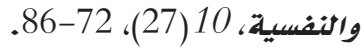

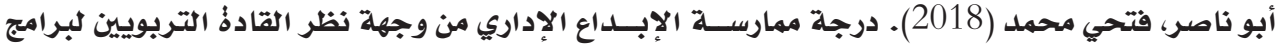

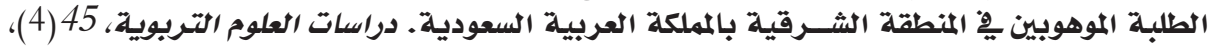
$.583-570$ 


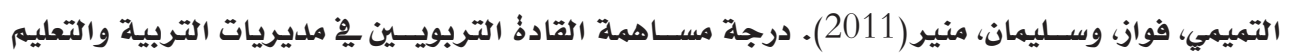

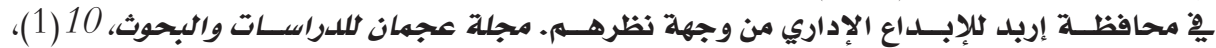
.114-99

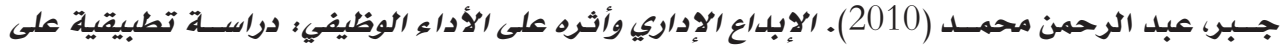

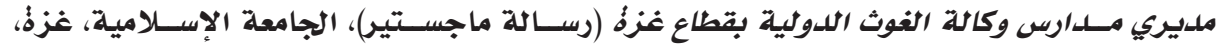
فلسطين.

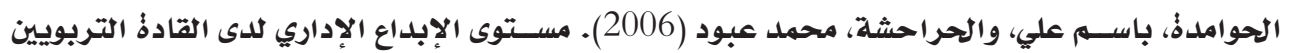

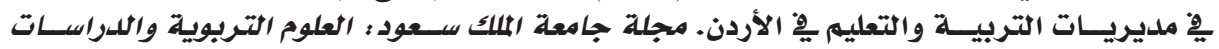

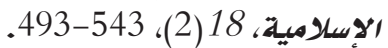

خير الله، جمال (2015). الإبلاع الإداريي (الطبعة الثانية).

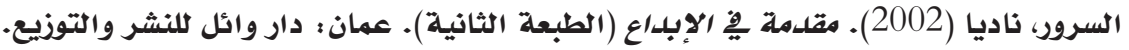

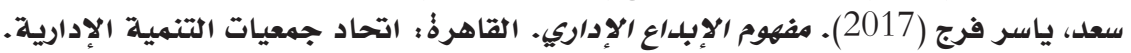

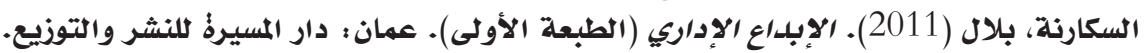

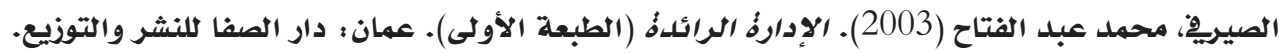

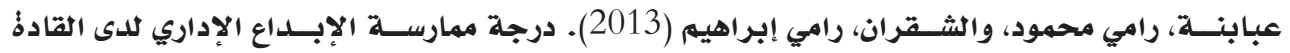

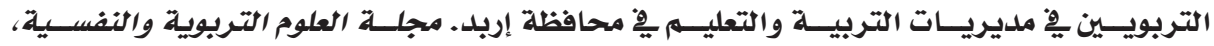
.686-459، (2)14 14

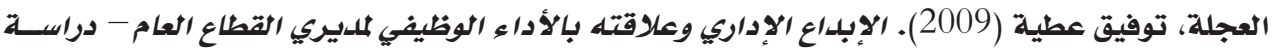

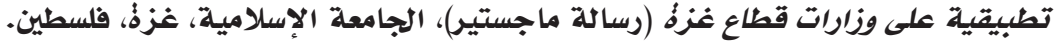

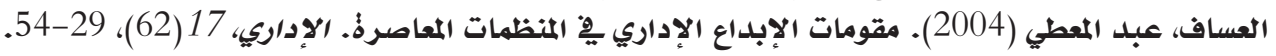
العميان، محمد (2002). السلوك التنظيهي فِ منظمات الأعمال (الطبعة الرابعة). والتوزيع.

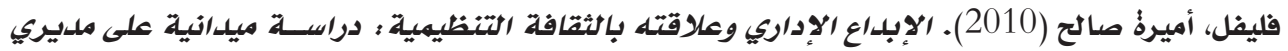

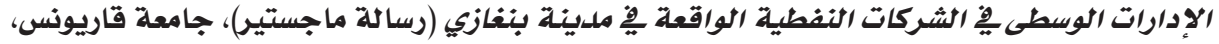
ليبيا.

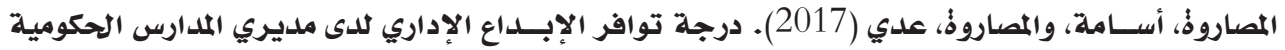

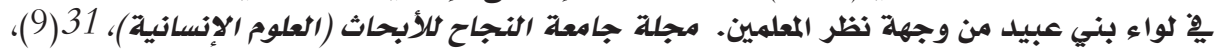
1526-1556 لواء عبيدال

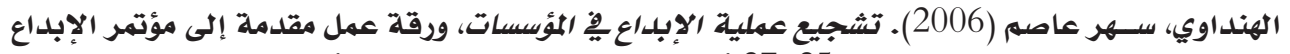
والتحول الإداري والاقتصادي، 25-27 أبريل، جامعة اليرموك، إعادية إربد، الأردن.

Abdul-Aal, A. M. A., \& saleh Alshammri, F. (2018). The Reality of Administrative Creativity among the Principals of General Secondary Education Schools: A Field Study in Sohag City. Global Journal of Management and Business Research, 18(13), 17-23.

Aburuman, N. M. (2016). The impact of administrative empowerment on creativity improvement among the workers of Jordanian public administration institute. International Journal of Business and Social Science, 7(1), 182-190. 
سلوى عايد السليحي

المجلد الثاني عشر العدد (22) 2021م

Elidemir, S. N., Ozturen, A., \& Bayighomog, S. W. (2020). Innovative behaviors, employee creativity, and sustainable competitive advantage: A moderated mediation. Sustainability, 12(8), 3295.

Muzzio, H., \& Paiva Júnior, F. G. (2018). Organizational Creativity Management: Discussion Elements. Revista de Administração Contemporânea, 22(6), 922-939.

Nwoko, N. L. (2017). Creative skills of principals for effective administration of public secondary schools in Abia State. Journal of Teacher Perspective, 12(2), 1-10.

Sousa, F. C., Nunes, F., \& Monteiro, I. (2019). Managers' attitudes to creativity and innovation practices in the creative industries. Tourism \& Management Studies, 15(1SI), 33-41.

Vecchio, C. (1991). Organizational behavior (2 ${ }^{\text {nd }}$ ed.). New York: Dryden Press.

\section{Arabic References in Roman Scripts:}

Ababneh, Rami Mahmoud, wa Al-Shaqran, Rami Ibrahim (2013). Darajat mumarasat al'iibdae al'iidarii ladaa alqadat altarbawiiyn fi mudiriaat altarbiat waltaelim fi muhafazat Irbid. Majalat Alulum Altarbawiat Walnafsiati, 14(2), 459-686.

Abu Hamdi, Ilham Nayef (2009). Waqie al'iibdae al'iidarii fi mudiriat altarbiat waltaelim fi muhafazat alaqabat bi Al-'Urduni min wijhat nazar alamilin fiha. Majalat Jamieat Alqudus Almaftuhat Lil'abhath Waldirasat Altarbawiat Walnafsiati, 10(27), 72-86.

Abu Nasser, Fathi Mohammed (2018). Darajat mumarasat al'iibdae al'iidarii min wijhat nazar alqadat altarbawiiyn libaramii altalabat almawhubin fi almintaqat alsharqiat bi Almamlakat Alarabiat Alsaeudiati. Dirasat Alulum Altarbawiati, 45(4), 570-583.

Al-Ajla, Tawfiq Attia (2009). Al'iibdae al'iidariu waealaqatuh bial'ada' alwazifii limudiri alqitae aleami - Dirasat tatbiqiat alaa wizarat qitae Ghaza (Risalat majistir), Aljamieat Al'iislamiati, Ghaza, Filastin.

Al-Amyan, Muhammad (2002). Alsuluk altanzimiu fi munazamat al'amal (altabeat alraabieatu). Amman: Dar Wayil Lilnashr Waltawziei.

Al-Assaf, Abdel-Moati (2004). Muqawimat al'iibdae al'iidarii fi almunazamat almueasirati. Al'iidari, 17(62), 29-54.

Al-Hawamdeh, Bassem Ali, wa Al-Harahsheh, Muhammad Abboud (2006). Mustawaa al'iibdae al'iidarii ladaa alqadat altarbawiiyn fi mudiriaat altarbiat waltalim fi Al-'Urduni. Majalat Jamieat Almalik Saeud: Alulum Altarbawiat Waldirasat Al'iislamiati, 18(2), 543-493. 
Al-Hindawi, Sahar Asim (2006). Tashiie eamaliat al'iibdae fi almuasasati. Waraqat amal muqadimat 'iilaa Mutamar Al'iibdae Waltahawul Al'iidarii Walaiqtisadii, 25-27 Abril, Jamieat Alyrmuk, Irbd, Al-'Urdun.

Al-Masarwe, Osama, wa Al-Masarwe, Uday (2017). Darajat tawafur al'iibdae al'iidarii ladaa mudiri almadaris alhukumiat fi liwa' bani eubayd min wijhat nazar almualimina. Majalat Jamieat Alnajah Lil'abhath (Alulum al'iinsaniati), 37(9), 1526-1556.

Al-Surour, Nadia (2002). Muqadimat fi al'iibdae (Altabeat althaaniatu). Amman: Dar Wayil Lilnashr Waltawziei.

Al-Tamimi, Fawaz, wa Suleiman, Mounir (2011). Darajat musahamat alqadat altarbawiiyn fi mudiriaat altarbiat waltaelim fi muhafazat Irbid lil'iibdae al'iidarii min wijhat nazarihim. Majalat Ajman Lildirasat Walbuhuth, 10(1), 99-114.

El-Serafy, Mohamed Abdel-Fattah (2003). Al'iidaratalraayida (Altabeat al'uwlaa). Amman: Dar Alsafa Lilnashr Waltawziei.

Fleifel, Amira Saleh (2010). Al'iibdae al'iidari waealaqatuh bialthaqafat altanzimiati: Dirasat maydaniat alaa mudiri al'iidarat alwustaa fi alsharikat alnaftiat alwaqieat fi madinat banghazi (Risalat majistir), Jamieat Qaryuns, Libia.

Gabr, Abdulrahman Muhammad (2010). Al'iibdae al'iidarii wa'atharuh alaa al'ada' alwazifi: Dirasat tatbiqiat alaa mudiri madaris Wikalat Alghawth Alduwliat biqitae Ghaza (Risalat Majistir), Aljamieat Al'iislamiati, Ghaza, Filastin.

Khairallah, Jamal (2015). Al'iibdae al'iidariv (Altabeat althaaniatu). Amman: Dar Osama Lilnashr Waltawziei.

Saad, Yasser Farag (2017). Mafhum al'iibdae al'iidari. Alqahirata: Aitihad Jameiaat Altanmiat Al'iidariati.

Sakarna, Bilal (2011). Al'iibdae al'iidariu (Altabeat al'uwlaa). Amman: Dar Almasirat Lilnashr Waltawziei. 